\title{
Inhibition, Reinforcement Sensitivity and Temporal Information Processing in ADHD and ADHD+ODD: Evidence of a Separate Entity?
}

\author{
Marjolein Luman • Steffen J. P. van Noesel • \\ Alky Papanikolau • \\ Janneke Van Oostenbruggen-Scheffer • \\ Diane Veugelers • Joseph A. Sergeant • Jaap Oosterlaan \\ Published online: 20 June 2009 \\ (C) The Author(s) 2009. This article is published with open access at Springerlink.com
}

\begin{abstract}
This study compared children with ADHD-only, ADHD+ODD and normal controls (age 8-12) on three key neurocognitive functions: response inhibition, reinforcement sensitivity, and temporal information processing. The goal was twofold: (a) to investigate neurocognitive impairments in children with ADHD-only and children with ADHD+ODD, and (b) to test whether ADHD+ODD is a more severe from of ADHD in terms of neurocognitive performance. In Experiment 1, inhibition abilities were measured using the Stop Task. In Experiment 2, reinforcement sensitivity and temporal information processing abilities were measured using a Timing Task with both a reward and penalty condition. Compared to controls, children with ADHD-only demonstrated impaired inhibitory control, showed more time underestimations, and showed performance deterioration in the face of reward and penalty. Children with ADHD+ODD performed inbetween children with ADHD-only and controls in terms of inhibitory controls and the tendency to underestimate time, but were more impaired than controls and children with ADHD-only in terms of timing variability. In the face of reward and penalty children with ADHD+ODD improved their performance compared to a neutral condition, in
\end{abstract}

M. Luman $(\bowtie) \cdot$ S. J. P. van Noesel · J. A. Sergeant •

J. Oosterlaan

Department of Clinical Neuropsychology,

VU University Amsterdam,

Van der Boechorststraat 1,

1081 BT Amsterdam, The Netherlands

e-mail: m.luman@psy.vu.nl

A. Papanikolau · J. Van Oostenbruggen-Scheffer $\cdot$ D. Veugelers $\cdot$

J. Oosterlaan

De Bascule,

Academic Centre for Child- and Adolescent Psychiatry,

Amsterdam, The Netherlands contrast to children with ADHD-only. In the face of reward, the performance improvement in the ADHD+ODD group was disproportionally larger than that of controls. Taken together the findings suggest that, in terms of neurocognitive functioning, comorbid ADHD+ODD is a substantial different entity than ADHD-only.

Keywords ADHD · ODD · Comorbidity - Inhibition · Time production $\cdot$ Reward $\cdot$ Motivation $\cdot$ Reinforcement . Neuropsychology

\section{Introduction}

Attention-deficit/ hyperactivity disorder (ADHD) in children is a chronic childhood developmental disorder expressed in symptoms of inattention, hyperactivity, and impulsivity (APA 2000). There is large phenomenological overlap between ADHD and oppositional defiant disorder (ODD) with comorbidity rates of 30-90\% (Angold et al. 1999; Pliszka 2000). ODD is expressed as refusing to comply with rules, deliberately annoying others, and a frequent loss of temper. Several researchers have suggested common etiological factors that add to the development of ADHD and ODD. In particular, neurocognitive impairments may be a key route for the development of both disorders through the expression of genetic, perinatal and psychosocial influences (Barkley 1997; Castellanos and Tannock 2002; Loeber et al. 2000). Although many studies have investigated neurocognitive functions in ADHD and ODD (see meta-analyses Willcutt et al. 2008), studies into neurocognitive impairments in children with comorbid ADHD and ODD are scarce. Thus, it remains controversial whether the co-occurrence of ADHD and ODD represents a combination of both disorders, or a separate entity with a 
distinct neurocognitive functioning profile. Knowledge on comorbid ADHD and ODD has important clinical implications, since this comorbidity is associated with increased morbidity and disability in terms of psychiatric, family and social functioning as compared to ADHD alone, even in the absence of conduct problems (Biederman et al. 1996).

Executive functioning (EF) is a well studied domain of neurocognitive functioning in ADHD and ODD (e.g., Barkley 1997; Morgan and Lilienfeld 2000; Oosterlaan et al. 2005; Pennington and Ozonoff 1996). EF comprises a set of higher order cognitive abilities that enable goal directed behavior and problem solving (Pennington and Ozonoff 1996), subserved by the prefrontal cortex and its subcortical connections (Casey et al. 2007; SemrudClikeman et al. 2000). In particular, inhibitory control is thought to be a key function, fundamental for the later emergence of other aspects of EF (Barkley 1997). The Stop Task allows measurement of the latency of the covert inhibitory response (Logan et al. 1984) and several studies reported on impaired Stop Task performance in children with ADHD and children with ODD (Albrecht et al. 2005; Alderson et al. 2007; Logan et al. 1997; Scheres et al. 2001). In a meta-analysis of the Stop Task, Oosterlaan et al. (1998) concluded that both disorders are associated with inhibitory deficits, although the evidence for ADHD is stronger than for ODD. In contrast, a recent meta-analysis of EF functions such as inhibitory control revealed that ADHD, not ODD is associated with EF problems (Willcutt et al. 2008). Thus, whether ADHD and ODD contribute jointly or independently to these problems is unclear. There are two studies comparing children with ADHD-only and ADHD+ODD on the Stop Task with conflicting results: One study reported intact inhibitory control in both clinical groups (Scheres et al. 2001), while the other reported problems in children with ADHD-only, but not in children with ADHD+ODD (e.g., Albrecht et al. 2005).

In addition to $\mathrm{EF}$, researchers have related ADHD and ODD to a motivational deficit (Newman and Wallace 1993; Quay 1997; Raine 1993; Sergeant et al. 1999; SonugaBarke 2002). An unusual sensitivity to motivational incentives is suggested to result in excessive rewardseeking behavior and impulsive tendencies in the presence of reward, as well as a decreased sensitivity to penalty. In ADHD there are reports of a strong preference for immediate over delayed reward, even when the delayed reward is larger (see for review Luman et al. 2005). This is explained by an aversion for waiting and a decreased sensitivity to cues that predict rewards (Sagvolden et al. 2005; Sonuga-Barke 2002; Tripp and Wickens 2008). Aggressive and delinquent youngsters are found to search for reward, irrespective of decreased total gain and increasing penalty (Daugherty and Quay 1991; Fonseca and Yule 1995; Matthys et al. 1998; O’Brien and Frick
1996). This is explained by a decreased emotional reactivity to the negative consequences of reward-searching behavior (Raine 1993), and researchers argue that, due to comorbid ODD, similar processes explain reward-searching behavior in ADHD (e.g., Daugherty and Quay 1991). Indeed, there is some evidence of decreased sensitivity to aversive stimuli in ADHD+ODD (Herpertz et al. 2001); a rewardimmediacy effect in ODD is not supported so far (Van Goozen et al. 2004).

A third potentially underlying neurocognitive deficit in ADHD and ODD is a deficit in temporal information processing (Castellanos and Tannock 2002; Dougherty et al. 2007). Temporal information processing is the ability to order sequential events in time and the ability to create rhythms; skills that depend on intact time perception, time discrimination and time (re)production (Ivry 1996). There is evidence of temporal information processing impairments in children with ADHD and adolescents with anti-social behavior in terms of an internal clock that runs too fast (Barratt and Patton 1983; Dougherty et al. 2007; Toplak et al. 2006), and a decreased stability of time estimation output (Dougherty et al. 2007; Luman et al. 2008). Thus, in these groups time seems to elapse too quickly and too variably, which may explain their problems with waiting and planning (APA 2000). Whether problems with temporal information processing are more related to ADHD or ODD is unclear, since studies comparing children with (ADHD+) ODD and ADHD-only are absent so far.

In sum, studies strongly suggest neurocognitive impairments in ADHD compared to typical development, but it is unclear whether children with ADHD+ODD are impaired and to what extent. Thus, the aim of this study was twofold: (a) to investigate neurocognitive impairments in ADHDonly and ADHD+ODD by assessing three key neurocognitive functions: response inhibition, reinforcement sensitivity, and temporal information processing, and (b) to test whether ADHD+ODD is a more severe from of ADHD in terms of neurocognitive performance, in line with observed increased disability in ADHD+ODD at other levels of performance (Biederman et al. 1996). In Experiment 1, inhibition abilities were measured using the Stop Task. In Experiment 2, groups were compared in terms of time production abilities and reinforcement sensitivity using a Time Production Task that was administered under a reward and penalty condition (Luman et al. 2008). If comorbid ADHD+ODD constitutes of a more severe form of ADHD, we expect impaired performance in both clinical groups compared to controls (e.g., Dougherty et al. 2007; Logan et al. 1997; Newman and Wallace 1993; SonugaBarke 2002; Toplak et al. 2006), but with a more deviant pattern of deficits observed in ADHD+ODD than the ADHD-only group. The unique contribution of this study is that it directly compares ADHD and ADHD+ODD on 
three key neurocognitive functions that have not been investigated in concert so far.

\section{Methods Experiment 1}

Participants and Selection Procedure

Thirty-eight children with ADHD (69\% boys) with either only a diagnosis of ADHD $(n=20)$ or ADHD and comorbid ODD $(n=18)$ were compared to 50 typically developing (TD) children (56\% boys) aged 7 to 12 . Inclusion criteria were: (a) estimated IQ score $>75$, (b) absence of a diagnosis of internalizing problems, history of child abuse, or psychiatric disorder other than ADHD or ODD, (c) absence of any neurological disorders, learning disabilities (such as dyslexia), sensory or motor impairment as reported by parents, (d) no medication other than methylphenidate. Group characteristics are reported in Table 1.

Children with ADHD were recruited through a university-affiliated outpatient clinic for children with behavior problems and by the national parents' association for children with developmental problems. Children were included, if they were clinically diagnosed with ADHD or ADHD+ODD by a health care professional. The assessment procedure consisted of three stages. Firstly, the diagnosis was confirmed by a clinical score ( $>95$ th percentile; see Table 1) on the ADHD, or ADHD and ODD scale of both the parent and teacher version of the Disruptive Behaviour
Disorder rating scale (DBD; Pelham et al. 1992). Secondly, parents were administered the Disruptive Behavior Disorders section of the Diagnostic Interview Scale (DISC-IV; Shaffer et al. 2000) to further assess their child's behavior. The DISC-IV is based on the Diagnostic and Statistical Manual of Mental disorders, fourth edition (DSM-IV; APA 2000). The DISC-IV confirmed the ADHD diagnoses in the ADHD-only group (6 children met criteria for ADHD comorbid type, 8 for ADHD inattentive type, 4 for ADHD hyperactive/impulsive type) and ADHD and ODD in the ADHD+ODD group (11 children met criteria for ADHD comorbid type, 4 for ADHD inattentive type, 3 for ADHD hyperactive/impulsive type). None of the children met criteria for comorbid conduct disorder (CD). Finally, to study a more homogeneous group of children with ADHD, the Dutch version of the Child Behavioral Checklist (CBCL) and Teacher Rating Form (TRF) were administered (Achenbach and Edelbrock 1981) to exclude children with clinical scores on the Anxious/Depressed, Thought Problems, or Somatic Complaints scales $(\mathrm{T}>70)$. TD children (control group) were recruited through local elementary schools. They were included, when their scores on all scales of the parent and teacher DBD were in the normal range $(<90$ th percentile).

All children who were on methylphenidate discontinued use at least $24 \mathrm{~h}$ before testing, to achieve complete washout (Pelham et al. 1999). An estimation of the IQ score of each child was obtained by four subtests (Picture Arrangement, Arithmetic, Block Design, and Vocabulary)
Table 1 Group Characteristics Experiment 1

$A D H D$ Attention-deficit/hyperactivity disorder; $C D$ Conduct disorder; $D B D$ Disruptive behaviour disorder rating scale; DISC Diagnostic interview scale for children; $T D$ Typical development.

${ }^{\text {a }}$ Groups were compared using ANOVA; Tukey's procedure was used for pair-wise group comparisons.

${ }^{\mathrm{b}}$ Raw scores are tabulated.

$*=p<0.05, * *=p<0.01, * * *=$ $p<0.001$.

\begin{tabular}{|c|c|c|c|c|c|c|c|}
\hline \multirow[b]{3}{*}{ Measure } & \multirow{2}{*}{\multicolumn{2}{|c|}{$\frac{\mathrm{ADHD}}{(n=20)}$}} & \multirow{2}{*}{\multicolumn{2}{|c|}{$\frac{\mathrm{ADHD}+\mathrm{ODD}}{(n=18)}$}} & \multirow{2}{*}{\multicolumn{2}{|c|}{$\begin{array}{l}\text { TD } \\
(n=50)\end{array}$}} & \multirow[t]{3}{*}{ Group comparison $^{\mathrm{a}}$} \\
\hline & & & & & & & \\
\hline & $M$ & $S D$ & $M$ & $S D$ & $M$ & $S D$ & \\
\hline Age in months & 106 & 17 & 118 & 18 & 114 & 15 & ADHD+ODD, TD>ADHD* \\
\hline IQ & 99.9 & 10.7 & 94.1 & 14.4 & 110.2 & 13.6 & $\mathrm{TD}>\mathrm{ADHD}, \mathrm{ADHD}+\mathrm{ODD} * *$ \\
\hline \multicolumn{8}{|l|}{ DBD Parent ${ }^{\mathrm{b}}$} \\
\hline Inattention & 15.7 & 4.4 & 16.9 & 4.5 & 1.9 & 2.1 & $\mathrm{ADHD}, \mathrm{ADHD}+\mathrm{ODD}>\mathrm{TD}^{* * *}$ \\
\hline Hyper/Impulsivity & 13.1 & 5.3 & 16.7 & 5.0 & 2.2 & 1.9 & $\mathrm{ADHD}+\mathrm{ODD}>\mathrm{ADHD}>\mathrm{TD} * * *$ \\
\hline ODD & 3.6 & 2.7 & 13.1 & 4.1 & 1.5 & 2.0 & $\mathrm{ADHD}+\mathrm{ODD}>\mathrm{ADHD}>\mathrm{TD} * * *$ \\
\hline $\mathrm{CD}$ & 0.6 & 0.8 & 3.5 & 2.6 & 0.1 & 0.4 & $\mathrm{ADHD}+\mathrm{ODD}>\mathrm{ADHD}, \mathrm{TD}^{* * *}$ \\
\hline \multicolumn{8}{|l|}{ DBD Teacher ${ }^{\mathrm{b}}$} \\
\hline Inattention & 17.3 & 4.3 & 13.9 & 5.2 & 1.6 & 2.5 & $\mathrm{ADHD}>\mathrm{ADHD}+\mathrm{ODD}>\mathrm{TD} * * *$ \\
\hline Hyper/Impulsivity & 13.2 & 7.1 & 14.0 & 5.4 & 0.7 & 1.8 & $\mathrm{ADHD}, \mathrm{ADHD}+\mathrm{ODD}>\mathrm{TD} * * *$ \\
\hline ODD & 3.9 & 5.1 & 12.1 & 5.3 & 0.9 & 1.9 & $\mathrm{ADHD}+\mathrm{ODD}>\mathrm{ADHD}>\mathrm{TD} * * *$ \\
\hline $\mathrm{CD}$ & 0.6 & 1.1 & 2.2 & 2.1 & $<0.1$ & 0.2 & $\mathrm{ADHD}+\mathrm{ODD}>\mathrm{ADHD}, \mathrm{TD}^{* * *}$ \\
\hline \multicolumn{8}{|l|}{ DISC $^{b}$} \\
\hline Inattention & 13.4 & 4.2 & 14.1 & 3.3 & - & - & ns \\
\hline Hyper/ Impulsivity & 9.8 & 5.0 & 13.0 & 4.5 & - & - & $\mathrm{ADHD}+\mathrm{ODD}>\mathrm{ADHD} *$ \\
\hline ODD & 0.6 & 0.8 & 5.0 & 2.0 & - & - & $\mathrm{ADHD}+\mathrm{ODD}>\mathrm{ADHD} *$ \\
\hline $\mathrm{CD}$ & 0.0 & 0.0 & 0.2 & 0.5 & - & - & ns \\
\hline
\end{tabular}


of the Wechsler Intelligence Scale for Children (WISC-III). These four subtests have been demonstrated to correlate between 0.93 and 0.95 with full scale IQ (Groth-Marnat 1997).

\section{Stop Task}

A tracking version of the Stop Task was used (Logan et al. 1997) consisting of go-trials $(75 \%)$ and stop-trials $(25 \%)$. On go-trials, children saw a fixation point presented for $500 \mathrm{~ms}$. The fixation point was followed by a go-stimulus, a picture of an airplane, that was displayed for $1,000 \mathrm{~ms}$ and presented in the center of the screen. In response to the go-stimulus, children were required to press a response button that corresponded to the direction the plane was flying in (left or right). The inter-stimulus interval was $1,500 \mathrm{~ms}$; the inter-trial interval was $3,000 \mathrm{~ms}$. On stoptrials, a white cross was superimposed on the go-stimulus and acted as stop-signal. Children were instructed not to press any button, when a trial contained a stop-signal. The Stop Task started with a practice block containing only go trials (64 trials), followed by a practice block also containing stop trials (64 trials). After the practice blocks 248 trials were presented in four blocks of 64 trials lasting approximately $5 \mathrm{~min}$ per block. Trials were presented in a semi-random fixed order.

The longer the delay between go- and stop-signal (the stop-signal-delay, SSD), the more difficult it is to inhibit the response. To ensure that the percentage of inhibited responses was $50 \%$ for each individual child, SSD was systematically varied. If children inhibited correctly, SSD lengthened by $50 \mathrm{~ms}$; if children failed to inhibit their response, SSD shortened by $50 \mathrm{~ms}$. Thus, most often the stop-signal was presented shortly after the airplane was displayed, but the stop-signal could also be presented concurrently or shortly before the airplane, depending on the performance of the child. The 'horse race' model of the Stop Task (Logan et al. 1984), which assumes a race between the reaction to the go-stimulus and the reaction to the stop-signal, allows estimating the 'virtual' reaction time to the stop-signal (SSRT), as a measure for response inhibition performance. When both the go and stop process have an equal probability of winning the race (by varying the SSD within each child, the percentage of inhibited responses is $50 \%$ ), SSRT should be approximately equal to the response to the go-stimulus minus SSD. Therefore, for each individual child, SSRT was obtained by calculating the difference between mean RT on go-trials and the mean SSD. For further details on the stop task and calculation of SSRT, please see Logan et al. (1984).

Mean RT and SD of RT on go-trials as well as percentage of errors were obtained as additional measures of response execution.

\section{Procedure}

Parents completed a written informed consent prior to the study that was approved by the local ethics committee. Travel costs were funded. Both experiments were part of a larger study on cognitive control problems in children with disruptive behavior problems. During the experiment, children viewed a computer screen positioned $60 \mathrm{~cm}$ in front of them. Standardized instructions were used. At the end of the session, children received a small gift worth approximately $€ 3$. Parents received a report detailing the findings of the study.

\section{Statistical Analyses}

Data of the dependent variables were compared between groups (ADHD-only, ADHD+ODD and TD) using ANOVA. If the group effect was significant, post-hoc analyses (Tukey procedure) were used to perform groupwise comparisons. Since children in the ADHD-only group were younger than the ADHD+ODD and TD group, and since the clinical groups had a lower estimated IQ score than controls, age and IQ were inserted as covariates in the ANOVA. Results showed that the covariates did not significantly change the $F$-values of the dependent variables, and therefore ANOVA results are presented in the Results section without the covariates. Effect sizes (partial eta squared) are reported to indicate the size of the effect being either small (0.01), medium (0.06), or large (0.14) (Cohen 1988).

\section{Results Experiment 1}

As hypothesized, both clinical groups group obtained higher scores on the ADHD and ODD scales of the parent and teacher DBD than controls (see Table 1), supporting phenomenological distinctiveness. In addition, children with ADHD+ODD obtained higher scores than children with ADHD-only on the ODD and CD scale of the parent and teacher DBD, as well as higher ODD ratings on the DISC. The ADHD and ADHD+ODD group differed in ADHD ratings: the ADHD-only group showed higher ratings of inattention on the parent $\mathrm{DBD}$ and lower hyperactivity/impulsivity ratings on the teacher DBD and DISC.

Stop Task Performance Group comparisons indicated that children with ADHD-only were slower and more variable on go-trials, and importantly, showed a slower SSRT than the TD group (see Table 2). Children with ADHD+ODD were also slower and more variable on go-trials than controls, and made more errors (combination of omissions 
Table 2 Stop Task Performance Experiment 1

\begin{tabular}{|c|c|c|c|c|c|c|c|c|c|}
\hline \multirow[t]{3}{*}{ Variable } & \multirow{2}{*}{\multicolumn{2}{|c|}{$\frac{\text { ADHD }}{(n=20)}$}} & \multirow{2}{*}{\multicolumn{2}{|c|}{$\frac{\mathrm{ADHD}+\mathrm{ODD}}{(n=18)}$}} & \multirow{2}{*}{\multicolumn{2}{|c|}{$\frac{\mathrm{TD}}{(n=50)}$}} & \multicolumn{3}{|c|}{ Group comparison } \\
\hline & & & & & & & \multirow[b]{2}{*}{$F(2,85)$} & \multirow[b]{2}{*}{$\eta_{\mathrm{p}}^{2}$} & \multirow[b]{2}{*}{ Post-hoc (Tukey) } \\
\hline & $M$ & $S D$ & $M$ & $S D$ & $M$ & $S D$ & & & \\
\hline SSRT (ms) & 315 & 77 & 275 & 90 & 247 & 56 & $6.4^{* *}$ & 0.13 & $\mathrm{ADHD}>\mathrm{TD}$ \\
\hline MRT (ms) & 651 & 109 & 657 & 105 & 547 & 97 & $12.2 * * *$ & 0.22 & $\mathrm{ADHD}, \mathrm{ADHD}+\mathrm{ODD}>\mathrm{TD}$ \\
\hline$S D$ of RT (ms) & 153 & 34 & 169 & 37 & 111 & 26 & $31.3 * * *$ & 0.42 & $\mathrm{ADHD}, \mathrm{ADHD}+\mathrm{ODD}>\mathrm{TD}$ \\
\hline Errors $(\%)$ & 3.4 & 2.5 & 6.7 & 7.1 & 1.7 & 1.5 & $12.9 * * *$ & 0.23 & $\mathrm{ADHD}+\mathrm{ODD}>\mathrm{ADHD}, \mathrm{TD}$ \\
\hline
\end{tabular}

$A D H D$ Attention-deficit/hyperactivity disorder; MRT Mean response time; ODD Oppositional Defiant Disorder; SSRT Stop signal response time; $T D$ Typical development.

${ }^{*} p<0.05,{ }^{* *} p<0.01, * * * p<0.001$

and commissions) than both controls and children with ADHD-only. Despite the slow, variable and incorrect responses, children with $\mathrm{ADHD}+\mathrm{ODD}$ were not slower in terms of SSRT. SSRT of the ADHD+ODD group lay in between that of the ADHD-only and the TD group, as both group comparisons with the ADHD+ODD group were nonsignificant. Finally, children with ADHD-only and children with ADHD+ODD did not differ in speed and variability of responses on go-trials.

\section{Discussion Experiment 1}

The results demonstrated inhibition problems (slower SSRT) in ADHD-only, but not in ADHD+ODD. Impaired inhibition performance in the ADHD-only group replicates earlier findings (Oosterlaan et al. 1998; Willcutt et al. 2008), and confirms inhibition problems as an important neurocognitive disability in ADHD. This difficulty with inhibiting an initiated motor response, may partly explain the behavioral symptoms of impulse control (APA 2000). Imaging data of the Stop Task in children with ADHD (Rubia et al. 2008) suggest that children with ADHD-only show underactivation of the dorsolateral prefrontal cortex during inhibition, a brain area that is found to play a major role in explaining impulsive and hyperactive behavior in ADHD (Bush et al. 2005; Seidman et al. 2005). The difficulties with inhibiting a motor response in the ADHD-only group may have been caused by 'poor motor control', since their responses to go trials were slower and more variable than those in the TD group. However, also children with ADHD+ODD showed poor motor control, while showing intact SSRT.

Intact inhibition in the ADHD+ODD group in contrast to the ADHD-only group implies that this function is more related to ADHD than ODD, which is reported in earlier studies (Alderson et al. 2007; Logan et al. 1997; Scheres et al. 2001). Results of a recent meta-analysis suggest that EF impairments in ODD, thus not only inhibition, are related to comorbid ADHD (Willcutt et al. 2008), which argues against the hypothesis that the variance in EF is more related to aggression than hyperactivity (Séguin et al. 2004). The difference in inhibition performance between the ADHD-only and ADHD+ODD group suggests that comorbid ADHD+ODD is not a more severe form of ADHD. As the data show, children with comorbid ADHD+ODD had larger error-rates than children with ADHD-only and controls, while showing similar SSRT. Possibly, children with ADHD+ODD used a different strategy than children with ADHD-only, such as not responding to go-signals (increasing the error-rate) in favor of accurate inhibitions. MRI studies using the Stop Task, report that $\mathrm{ADHD}$ and $\mathrm{CD}$ children differ in brain activation during inhibitions: while $\mathrm{CD}$ was more related to attention allocation problems as a result of deficits in the temporal-parietal lobe, ADHD was more related to inhibition problems as a result of deficits in the prefrontal cortex (Rubia et al. 2008). Although imaging studies in children with (ADHD+)ODD are missing so far, differences in brain activity between ADHD-only and ADHD+ODD may explain the observed differences in performance.

Reports on a lack of differentiation on stop task performance between ADHD and ADHD+ODD (see Scheres et al. 2001), could be related to differences in the Stop Task used. In the study by Scheres et al. (2001) the event rate manipulations may have 'activated children to perform well', which resulted in a lack of performance differences between the ADHD groups and the TD group.

\section{Methods Experiment 2}

Participants and Selection Procedure

In Experiment 2, 40 children with ADHD (75\% boys) with either a diagnosis of ADHD-only $(n=18)$ or a diagnosis of 
ADHD+ODD $(n=22)$ and 52 TD children ( $72 \%$ boys) participated. Nine children in the ADHD-only group met DISC criteria for ADHD combined type, 2 for ADHD inattentive type, 7 for ADHD hyperactive/impulsive type. Thirteen children in the ADHD+ODD group met DISC criteria for ADHD combined type, 5 for ADHD inattentive type, 4 for ADHD hyperactive/impulsive type. None of the children met DISC criteria for CD.

Fifteen children with ADHD+ODD and 22 TD children also participated in Experiment 1. Part of the data of the other children (18 children with ADHD-only, 7 children with ADHD+ODD, and 30 TD children) have been reported in an earlier paper of our group (Luman et al. 2008). Specifically, that paper reported on the data of 25 children with ADHD and 30 typically developing children who performed the Timing Task in both a reward and penalty condition. In that study, no differentiation was made between ADHD-only and ADHD+ODD. Selection criteria of all children were identical to those employed in Experiment 1. Group characteristics are reported in Table 3.

\section{Motivated Timing Task}

A self-paced Time Production Task was employed. In this task, children had to produce a time interval of $1,000 \mathrm{~ms}$ (see Fig. 1). Processing of intervals up to $1,000 \mathrm{~ms}$ is found to depend on activity in the cerebellum, while larger intervals depend more on activity in the prefrontal cortex (Ivry 1996) and choosing a 1-second interval minimizes the influence of working memory and sustained attention functions that are known to be impaired in children with ADHD. The trial started with a colored screen $(500 \mathrm{~ms})$ that indicated the reinforcement condition. A green screen signaled that the reward condition was applicable; a red screen signaled the penalty condition; a blue screen the feedback-only condition. Reinforcement information in the reward and penalty condition was presented in the centre of the colored screen (being either $+3,-3,+15,-15$ ). Children heard a brief tone $(50 \mathrm{~ms}, 80 \mathrm{db})$ through headphones. Following the tone, they pressed a response button that could be moved freely on the table, when they thought a $1,000 \mathrm{~ms}$ interval had elapsed. One thousand millisecond after the button press, textual accuracy information appeared on the screen for $500 \mathrm{~ms}$ that informed the subject whether the estimation was 'too short', 'too long' (both incorrect) or 'correct'. Accuracy information was provided on every trial. A staircase algorithm determined the time window in which a response was considered correct. The boundaries of the initial window were 500 and $1,500 \mathrm{~ms}$ and narrowed by $100 \mathrm{~ms}$, when a response was correct, while it widened by $100 \mathrm{~ms}$ when a response was incorrect (see Miltner et al. 1997). Consequently, this procedure ensured a similar amount of positive and negative feedback (and reward and penalty) for each participant. Depending on the reinforcement condition, coins indicating gain or loss appeared on the screen. In the reward condition, feedback was accompanied by a 3 or 15 cents gain when responses were correct, and children
Table 3 Group Characteristics Experiment 2

$A D H D$ Attention-deficit/ hyperactivity disorder; $C D$ Conduct disorder; $D B D$ Disruptive behaviour disorder rating scale; DISC Diagnostic interview scale for children; $T D$ Typical development.

${ }^{\text {a }}$ Groups were compared using an ANOVA, Tukey's procedure was used for pair-wise comparisons.

${ }^{\mathrm{b}}$ Raw scores are tabulated.

$*=p<0.05, * *=p<0.01, * * *=$ $p<0.001$.

\begin{tabular}{|c|c|c|c|c|c|c|c|}
\hline \multirow[t]{3}{*}{ Measure } & \multirow{2}{*}{\multicolumn{2}{|c|}{$\frac{\mathrm{ADHD}}{(n=18)}$}} & \multirow{2}{*}{\multicolumn{2}{|c|}{$\frac{\mathrm{ADHD}+\mathrm{ODD}}{(n=22)}$}} & \multirow{2}{*}{\multicolumn{2}{|c|}{$\begin{array}{l}\mathrm{TD} \\
(n=52)\end{array}$}} & \multirow[t]{3}{*}{ Group comparison $^{\mathrm{a}}$} \\
\hline & & & & & & & \\
\hline & $M$ & $S D$ & $M$ & $S D$ & $M$ & $S D$ & \\
\hline Age in months & 123 & 19 & 120 & 16 & 120 & 15 & ns \\
\hline IQ & 99.1 & 10.9 & 96.2 & 14.7 & 108.6 & 16.3 & $\mathrm{TD}>\mathrm{ADHD}+\mathrm{ODD} * *$ \\
\hline \multicolumn{8}{|l|}{ Rating scale parent $\mathrm{t}^{\mathrm{b}}$} \\
\hline Inattention & 18.4 & 4.1 & 14.2 & 5.3 & 2.6 & 2.7 & $\mathrm{ADHD}, \mathrm{ADHD}+\mathrm{ODD}>\mathrm{TD} * * *$ \\
\hline Hyper/Impulsivity & 15.8 & 7.2 & 13.9 & 5.1 & 2.1 & 2.0 & $\mathrm{ADHD}, \mathrm{ADHD}+\mathrm{ODD}>\mathrm{TD} * * *$ \\
\hline ODD & 6.3 & 4.6 & 10.8 & 5.5 & 1.7 & 1.9 & $\mathrm{ADHD}+\mathrm{ODD}>\mathrm{ADHD}>\mathrm{TD} * * *$ \\
\hline $\mathrm{CD}$ & 1.2 & 2.1 & 2.3 & 2.2 & 0.2 & 0.5 & $\mathrm{ADHD}+\mathrm{ODD}>\mathrm{ADHD}, \mathrm{TD} * * *$ \\
\hline \multicolumn{8}{|c|}{ DBD rating scale teacher ${ }^{\mathrm{b}}$} \\
\hline Inattention & 16.2 & 4.8 & 16.5 & 4.8 & 2.1 & 2.7 & $\mathrm{ADHD}, \mathrm{ADHD}+\mathrm{ODD}>\mathrm{TD} * * *$ \\
\hline Hyper/Impulsivity & 12.9 & 7.4 & 15.8 & 4.6 & 1.7 & 2.1 & $\mathrm{ADHD}, \mathrm{ADHD}+\mathrm{ODD}>\mathrm{TD} * * *$ \\
\hline ODD & 4.9 & 4.0 & 11.7 & 4.9 & 0.4 & 1.2 & $\mathrm{ADHD}+\mathrm{ODD}>\mathrm{ADHD}>\mathrm{TD} * * *$ \\
\hline $\mathrm{CD}$ & 0.6 & 1.1 & 2.9 & 2.6 & 0.1 & 0.3 & $\mathrm{ADHD}+\mathrm{ODD}>\mathrm{ADHD}, \mathrm{TD} * * *$ \\
\hline \multicolumn{8}{|l|}{ DISC $^{b}$} \\
\hline Inattention & 14.6 & 2.2 & 13.6 & 3.9 & - & - & ns \\
\hline Hyper/ Impulsivity & 10.8 & 5.7 & 12.7 & 4.2 & - & - & ns \\
\hline ODD & 1.8 & 1.1 & 5.0 & 4.7 & - & - & $\mathrm{ADHD}+\mathrm{ODD}>\mathrm{ADHD} * * *$ \\
\hline $\mathrm{CD}$ & 0.1 & 0.1 & 0.2 & 0.6 & - & - & ns \\
\hline
\end{tabular}




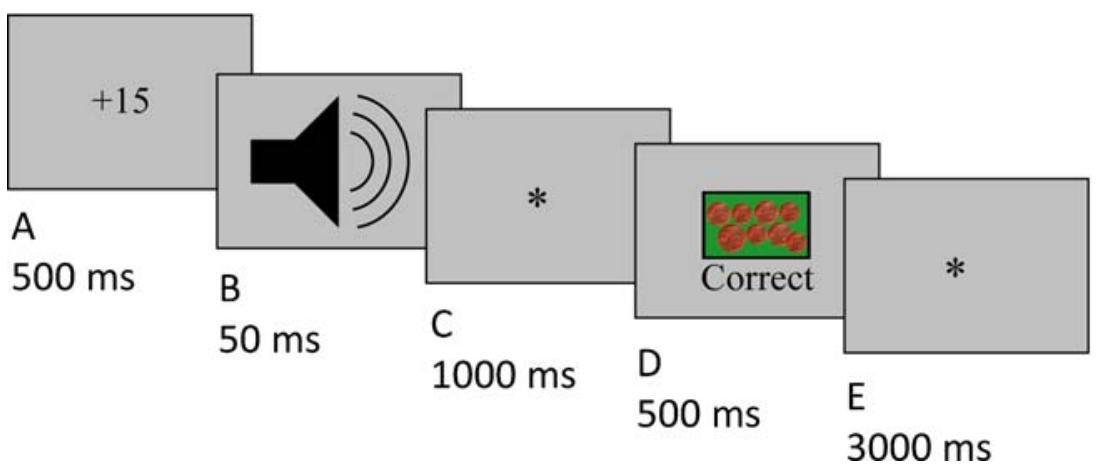

Fig. 1 The time-course of a time-production trial. a Background screen turned green (reward condition), red (penalty condition) or blue (feedback-only condition) for $500 \mathrm{~ms}$. Amount of reward and penalty was presented in the centre of the screen (being either $+3,-3,+15$, $-15)$. b Children heard an auditory beep for $50 \mathrm{~ms}$ indicating the start

received only feedback in case of an incorrect response. In the penalty condition, feedback was accompanied by a 3 or 15 cents loss when responses were incorrect, and children received only feedback following a correct response. The inter-trial interval was $3,000 \mathrm{~ms}$. Trials from the 5 reinforcement conditions (60 trials per condition) were presented in a random order.

At the beginning of the task, children received 200 eurocents, which was placed in their view. They were instructed to gain as much and lose as little as possible. Participants were informed that their earnings would be calculated at the end of the task. In order to familiarize children with the $1,000 \mathrm{~ms}$ interval, children saw a cartoon character that appeared 10 times on the screen for 1,000 ms. Thereafter, a practice session started in which children practiced the feedback-only trials ( 6 trials), followed by the reward trials (12 trials) and the penalty trials (12 trials). Finally, children practiced the randomized trials (12 trials). The task was presented in five blocks lasting approximately 6 min per block. At the end of the task, children were told that their net score was 245 eurocents, which was an (arbitrary) 45 cents gain. All children exchanged their 245 cents for a gift.

According to the Wing and Kristofferson model (1973) time productions consist of two independent aspects: internal clock functioning (a measure of central time keeping) and random variability due to execution of the motor response. Internal clock functioning was indexed by the median time production (investigating either over- or underproduction of time). Motor execution was indexed by the intra-subject variability (ISV), a measure of the trial-to-trial variability in performance that controls for the mean response (Russell et al. 2006). ISV $=\sqrt{ }\left(\sum\left(\mathrm{RT}_{\mathrm{i}}-\mathrm{RT}_{\mathrm{i}-1}\right)^{2} /(\mathrm{n}-1)\right)$, where $\mathrm{i}=$ trial number, $\mathrm{n}=$ number of trials, and $\mathrm{RT}=$ response time. Time productions longer than four standard deviations of a participant's mean were considered as outliers and excluded (see Leth-Steensen et al. 2000). In the ADHD-only of 1-s interval, after which they were required to press the response button. c A 1,000 ms screen with fixation cross separated the button press from feedback presentation. d Feedback appeared on the screen for $500 \mathrm{~ms}$. e The screen turned blank for 3,000 ms before the next trial started

group this was $0.7 \%$ of the data points, in the ADHD+ODD group $0.8 \%$, and in the TD group $0.1 \%$. Procedures were identical to Experiment 1.

\section{Statistical Analyses}

Data of the two timing variables were compared between groups (ADHD-only, ADHD+ODD and TD) using ANOVA. To investigate reinforcement sensitivity, performance of the groups was compared between the feedbackonly, reward condition (averaged over the 3 and 15 cent gain trials) and penalty condition (averaged over the 3 and 15 cent loss trials) using repeated measure ANOVA. If group effects were significant, post-hoc analyses (Tukey Procedure) were used for pair-wise group comparisons. Three planned contrasts were tested: (a) reward versus feedback-only to test the impact of reward, (b) penalty versus feedback-only to test the impact of penalty, and (c) reward versus penalty to test the impact of the valence of reinforcement. The planned contrasts were orthogonal (uncorrelated with) every other contrast (Kirk 1968). Since children in the ADHD+ODD group had lower IQs than the TD group, IQ was entered as covariate in the ANOVAs. Results showed that the covariate did not significantly change the $F$-values of the dependent variables, and therefore ANOVA results are presented in the Results section without IQ as covariate.

\section{Results Experiment 2}

As hypothesized, both clinical groups group obtained higher scores on the ADHD and ODD scales of the parent and teacher DBD than controls (see Table 3), supporting phenomenological distinctiveness. In addition, children with ADHD+ODD obtained higher scores than children with ADHD-only on the ODD and CD scale of the parent 
and teacher DBD, as well as a higher ODD ratings on the DISC.

\section{Timing Performance}

Group comparisons (see Table 4) indicated that both clinical groups underestimated the time interval compared to controls (lower median time production), although the difference between the ADHD+ODD and TD group was only of marginal significance. The difference in time underestimation between the ADHD-only and ADHD+ODD group was not significant. Time productions were more variable (larger timing ISV) for the ADHD+ODD group than for both the ADHD-only and the TD group. Time production variability of children with ADHD-only did not differ significantly from that of the TD group.

\section{Reinforcement Sensitivity}

Response to reward Overall, median time productions were closer to optimal $(1,000 \mathrm{~ms})$ in the face of reward compared to feedback-only, as indicated by a significant condition effect for the reward contrast, $F_{1,89}=23, p<0.001, \eta_{p}^{2}=$ 0.20 (not in Table 5). This effect differed between groups as children with ADHD+ODD profited more from reward in terms of decreasing their tendency to underestimate time than children with ADHD-only or controls (see Table 5). In contrast, children with ADHD-only performed worse in the face of reward than controls, as their tendency to underestimate time became larger in the reward trials compared to the feedback-only trials. For time production ISV, there was no significant difference between the reward and feedback-only condition $(p=0.72)$ and no significant interaction between the reward contrast and group.

Response to penalty Median time productions were closer to optimal $(1,000 \mathrm{~ms})$ in the face of penalty compared to feedback-only, as indicated by a significant condition effect for the penalty contrast, $F_{1,89}=35, p<0.001, \eta_{p}^{2}=0.29$ (not in Table 5). This effect differed between groups as children with ADHD-only profited less from penalty, in terms of decreasing their tendency to underestimate time, than children with ADHD+ODD or controls (see Table 5). There was no difference in penalty sensitivity between children with ADHD+ODD and controls. For time production ISV, there was no significant difference between the penalty and feedback-only condition $(p=0.91)$ and no significant interaction between the penalty contrast and group.

Reward versus Penalty Median time productions were closer to optimal $(1,000 \mathrm{~ms})$ in the face of penalty compared to reward, although this condition effect just escaped conventional levels of significance, $F_{1,89}=$ $3.1, p=0.08, \eta_{p}^{2}=0.03$ (not in Table 5). Groups did not differ in their sensitivity to reward versus penalty. For time production ISV, there was no significant difference between the reward and the penalty conditions $(p=0.93)$ and there was no significant interaction between the valence contrast and group.

\section{Discussion Experiment 2}

According to the model of Wing and Kristofferson (1973) intact time production requires an accurate internal clock and intact execution of motor responses. The internal clock includes the actual internal representation of time, and motor execution includes all that happens between the clock trigger and the response being executed. The findings show that, compared to TD children, (1) both clinical groups showed a faster internal clock, as indicated by greater underestimations of time, and (2) children with ADHD+ODD showed impaired execution of motor responses, as indicated by more variable time productions. The findings confirm that time passes faster in children with ADHD (comorbid with ODD) than controls (Dougherty et al. 2007; Toplak et al. 2006).

Table 4 Timing Performance Experiment 2

\begin{tabular}{|c|c|c|c|c|c|c|c|c|c|}
\hline \multirow[t]{3}{*}{ Variable } & \multirow{2}{*}{\multicolumn{2}{|c|}{$\frac{\mathrm{ADHD}}{(n=18)}$}} & \multirow{2}{*}{\multicolumn{2}{|c|}{$\frac{\mathrm{ADHD}+\mathrm{ODD}}{(n=22)}$}} & \multirow{2}{*}{\multicolumn{2}{|c|}{$\frac{\mathrm{TD}}{(n=52)}$}} & \multicolumn{3}{|c|}{ Group comparison } \\
\hline & & & & & & & & & \\
\hline & $M$ & $S D$ & $M$ & $S D$ & $M$ & $S D$ & $F(2,89)$ & $\eta_{\mathrm{p}}^{2}$ & Post-hoc (Tukey) \\
\hline $\operatorname{Median}(\mathrm{ms})^{\mathrm{a}}$ & 904 & 114 & 916 & 133 & 971 & 89 & $3.6^{*}$ & 0.08 & $\mathrm{ADHD}, \mathrm{ADHD}+\mathrm{ODD}<\mathrm{TD}^{\mathrm{b}}$ \\
\hline ISV (ms) & 325 & 133 & 648 & 507 & 280 & 108 & $15.2 * * *$ & 0.25 & $\mathrm{ADHD}+\mathrm{ODD}>\mathrm{ADHD}, \mathrm{TD}$ \\
\hline
\end{tabular}

$A D H D$ Attention-deficit/ hyperactivity disorder; ISV Intra-subject variability; ODD Oppositional Defiant Disorder; TD Typical development.

${ }^{\text {a }}$ The optimal response was $1,000 \mathrm{~ms}$.

${ }^{\mathrm{b}}$ The difference between ADHD+ODD and TD was marginally significant.

${ }^{*} p<0.05,{ }^{* *} p<0.01, * * * p<0.001$. 
Table 5 Timing Task Performance Experiment 2: Effects of Feedback-only, Reward and Penalty

\begin{tabular}{|c|c|c|c|c|c|c|}
\hline \multirow[t]{3}{*}{ Variable } & \multirow{2}{*}{$\frac{\mathrm{ADHD}}{(n=18)}$} & \multirow{2}{*}{$\frac{\mathrm{ADHD}+\mathrm{ODD}}{(n=22)}$} & \multirow{2}{*}{$\frac{\mathrm{TD}}{(n=52)}$} & \multicolumn{3}{|c|}{ Group comparison ${ }^{\mathrm{b}}$} \\
\hline & & & & & & \\
\hline & $M$ diff & $M \operatorname{diff}$ & $M$ diff & $F(2,89)$ & $\eta_{\mathrm{p}}^{2}$ & Post-hoc (Tukey) \\
\hline \multicolumn{7}{|l|}{ Median $(\mathrm{ms})^{\mathrm{a}}$} \\
\hline Reward-FB & $\begin{aligned} 872-936 & =-64 \\
(\mathrm{SD} & =80)\end{aligned}$ & $\begin{aligned} 915-879 & =36 \\
(\mathrm{SD} & =122)\end{aligned}$ & $\begin{aligned} 961-952 & =9 \\
(\mathrm{SD} & =62)\end{aligned}$ & $10.8^{* * *}$ & 0.19 & $\begin{array}{l}\mathrm{ADHD}<\mathrm{TD}<\mathrm{ADHD}+ \\
\mathrm{ODD}\end{array}$ \\
\hline Penalty-FB & $\begin{aligned} 920-936 & =-16 \\
(\mathrm{SD} & =49)\end{aligned}$ & $\begin{aligned} 935-879 & =56 \\
(\mathrm{SD} & =108)\end{aligned}$ & $\begin{aligned} 989-952 & =37 \\
(\mathrm{SD} & =64)\end{aligned}$ & $4.8 * *$ & 0.10 & $\begin{array}{l}\mathrm{ADHD}< \\
\mathrm{ADHD}+\mathrm{ODD}, \mathrm{TD}\end{array}$ \\
\hline Rew-Penalty & $\begin{aligned} 872-920 & =-48 \\
(\mathrm{SD} & =52)\end{aligned}$ & $\begin{array}{r}915-935=-20 \\
(\mathrm{SD}=100)\end{array}$ & $\begin{aligned} 961-989 & =-28 \\
(\mathrm{SD} & =64)\end{aligned}$ & 1.7 & 0.04 & - \\
\hline \multicolumn{7}{|l|}{ ISV (ms) } \\
\hline Reward-FB & $\begin{aligned} 309-411 & =-102 \\
(\mathrm{SD} & =231)\end{aligned}$ & $\begin{aligned} 598-732 & =-134 \\
(\mathrm{SD} & =446)\end{aligned}$ & $\begin{aligned} 269-301 & =-32 \\
(\mathrm{SD} & =147)\end{aligned}$ & 1.3 & 0.03 & - \\
\hline Penalty-FB & $\begin{aligned} 298-411 & =-113 \\
(\mathrm{SD} & =226)\end{aligned}$ & $\begin{aligned} 655-732 & =-77 \\
(\mathrm{SD} & =409)\end{aligned}$ & $\begin{aligned} 280-301 & =-21 \\
(\mathrm{SD} & =168)\end{aligned}$ & 0.9 & 0.02 & - \\
\hline Rew-Penalty & $\begin{aligned} 309-298 & =11 \\
(\mathrm{SD} & =101)\end{aligned}$ & $\begin{aligned} 598-655 & =-57 \\
(\mathrm{SD} & =297)\end{aligned}$ & $\begin{aligned} 269-280 & =-11 \\
(\mathrm{SD} & =101)\end{aligned}$ & 2.6 & 0.06 & - \\
\hline
\end{tabular}

$A D H D$ Attention-deficit/hyperactivity disorder; ISV Intra-subject variability; $O D D$ Oppositional defiant disorder; $T D$ Typical development.

${ }^{\mathrm{a}}$ The optimal response was $1,000 \mathrm{~ms}$.

${ }^{\mathrm{b}}$ The interaction between groups and condition was calculated using a repeated measure ANOVA.

${ }^{*} p<0.05,{ }^{* *} p<0.01,{ }^{* * *} p<0.001$.

Such an abnormally fast internal clock could explain overactive and impulsive behavior (acting 'too fast') in ADHD (comorbid with ODD) and the problems with waiting and planning (Oosterlaan et al. 2005; Sergeant et al. 2002). A faster execution of movements in children with ADHD (comorbid with ODD) is observed in difficulties with hand-motor coordination in sports or writing, which is often described as 'clumsy' behavior (Karatekin et al. 2003). The observation that time estimations of children with ADHD+ODD fell in-between those of children with ADHD-only and controls, suggests that comorbid ADHD+ODD is not a more severe form of ADHD in terms of timing performance. Increased variability in motor timing execution has been observed in many patient groups (see Stuss et al. 2003), including anti-social adolescents (Dougherty et al. 2007). This is the first study that demonstrates these problems in children with ODD (comorbid with ADHD). Many experimental studies on response variability have focused only on ADHD (e.g., Leth-Steensen et al. 2000; Russell et al. 2006), but our findings stress the importance of investigating the role of comorbid ODD.

Children with ADHD-only responded differently to reinforcement than children with ADHD+ODD, at least when the median time production was considered. Children with ADHD+ODD and controls decreased their tendency to underestimate time in the face of reward and penalty (median time production closer to $1,000 \mathrm{~ms}$ ), suggesting an increase in motivation to perform well. Children with ADHD-only, on the other hand, pressed the button too early in the prospect of winning and also in the prospect of loosing money, possibly because they were distracted by reinforcement stimuli (see Douglas 1989) or tried to avoid reward delay (see Sonuga-Barke 2002). The results suggest that children with ADHD+ODD and not children with ADHD-only are reward maximizers (the positive effect of reward was larger for children with $\mathrm{ADHD}+\mathrm{ODD}$ than for controls) at least as measured in an experimental setting. In the face of penalty, children with ADHD+ODD performed similarly to controls. Thus, no evidence was revealed that children with ADHD+ODD are less sensitive to penalty as observed in children with $\mathrm{CD}$. Children with $\mathrm{CD}$ are thought to show a smaller emotional response to threatrelated stimuli (Raine 1993), which may explain their diminished attention to penalty. This 'lack of fear' would not apply for children with ADHD+ODD in our study. Otherwise, a decreased sensitivity to penalty in children with (ADHD+)ODD may occur only in conflicting situations were both reward and penalty are available (Raine 1993). If replicated using ecological valid paradigms, these findings have important clinical implications for behavioral interventions that use reinforcement to shape behavior (see Clinical Implications). 
Taken together, children with ADHD-only seem distracted by reward and penalty, while children with ADHD + ODD seem to profit from reinforcement. Again, these findings argue against the idea that ADHD+ODD can be considered a more severe form of ADHD.

\section{General Discussion}

The goal of this study was twofold: (a) to investigate neurocognitive impairments in children with ADHD and children with ADHD+ODD and (b) to test whether ADHD $+\mathrm{ODD}$ is a more severe from of ADHD in terms of neurocognitive performance. Since studies of neurocognitive functioning in children with ADHD+ODD are currently lacking, the second aim of this study was of specific importance (Willcutt et al. 2008). The findings suggest that children with ADHD-only showed difficulties on all three neurocognitive functions: inhibition, timing (internal clock functioning) and reinforcement sensitivity. Children with ADHD+ODD were less impaired on inhibition and reinforcement sensitivity than children with ADHD-only, and were unique in their pattern of increased timing variability. Thus, the findings suggest that comorbid ADHD+ODD is a substantially different entity in terms of neurocognitive problems, and not a separate subgroup of ADHD with equal or more severe neurocognitive problems as compared to ADHD-only (Biederman et al. 1996). These findings stress the importance of investigating the role of comorbid ODD when studying these neurocognitive functions in ADHD.

The idea that comorbid ADHD+ODD is a different entity than ADHD-only is supported by electrophysiological studies that show different brain abnormalities in children with ADHD+ODD compared to children with ADHD-only or ODD-only (Banaschewski et al. 2003; Clarke et al. 2002). Children with ADHD-only, in contrast to the ADHD+ODD group, demonstrated attenuated electrophysiological responses (less P3 activation to cues) during a Continuous Performance Task (CPT; Banaschewski et al. 2003). These findings suggest problems with anticipation and preparation of responses in ADHD-only that are not observed in children with ADHD+ODD. Impaired anticipation and preparation of responses in ADHD-only may explain problems with response inhibition such as observed in the Stop Task.

Our findings have implications for the theories on the possible mechanisms of comorbidity between ADHD and ODD (see Rutter 1997). According to Rutter (1997) the first possibility is that the diagnostic distinction between ADHD and ODD is artefactual. In other words, both forms of psychopathology represent varied manifestations of the same general syndrome of disruptive behaviour, possibly with different peak ages of manifestation. Another option is that symptoms associated with ADHD provoke environmental factors that predisposes to ODD. For example, ADHD behaviour may provoke negative reactions from other people, that may lead to ODD symptoms. Our finding that ADHD+ODD is a less severe form of ADHD in terms of the three key neurocognitive functions studied here, may suggest the development of ADHD in children with ADHD + ODD differs from the development of ADHD in children with ADHD-only. The common etiological model for ADHD is that the disorder develops through heritable risk factors, which lead to neurocognitive dysfunctions which in turn lead to the symptoms of ADHD (Doyle et al. 2005). This model might not hold for comorbid ADHD+ODD. Possibly the development of ADHD in children with ADHD+ODD is the result of (negative) environmental factors, rather than neurocognitive deficiencies that result from risk genes for ADHD. This hypotheses is supported by lower heritability estimates for ADHD+ODD than for ADHD (Eaves et al. 1997; Thapar et al. 1999). This would argue for multiple developmental pathways for ADHD as has been suggested by others (Castellanos and Tannock 2002).

This study has some limitations. Firstly, the inclusion of a group of children with ODD-only would have enabled us to investigate whether ADHD+ODD is a separate entity, that differs from both ADHD and ODD (such as observed by Banaschewski et al. 2003). Secondly, in both Experiments groups differed in IQ, especially the group with ADHD+ODD showed a lower IQ than the TD group. A review of 27 studies (Hogan 1999) showed that $60 \%$ of the studies into IQ in relation to ADHD and ODD reported a significant negative relation between IQ and ADHD and IQ and ODD. Importantly, inserting IQ as a covariate in our analyses resulted in similar results as ANOVAs without IQ as covariate, indicating that the neurocognitive problems are robust and independent of IQ. A similar limitation is the difference in age in Experiment 1: Children with ADHD were almost a year younger than children with ADHD+ODD. Both groups were recruited from our outpatient clinic, where ADHD is usually diagnosed in development earlier than ODD. Despite the positive relation between age and SSRT, covarying for age left the findings unchanged. Finally, one may question whether the differences between ADHD-only and ADHD+ODD relate to differences in ADHD subtypes. In Experiment 1, children with ADHDonly showed higher (parent) ratings of inattention and lower ratings of hyperactivity/impulsivity than children with ADHD+ODD. Future studies should reveal whether problems with the response inhibition are more related to inattention than hyperactivity/impulsivity. And although no differences in ADHD-ratings were observed between the clinical groups in Experiment 2, recent findings suggest that altered reinforcement sensitivity is related to hyperactivity/ impulsivity, rather than inattention (Scheres et al. 2007). 
Clinical implications

Although confirmation of our findings is necessary in a community sample of children with ADHD (not only including children with ADHD symptoms above a certain cutt-off), the findings suggest that ADHD+ODD is not a more severe form of ADHD in terms of impairments in neurocognitive functioning. Since neurocognitive functions are of great importance for daily life functioning, affecting academic (e.g., Geary 1993), and social performance (Lezak 2004), assessing comorbid ODD in ADHD seems highly significant. Therefore, interventions that focus on training these neurocognitive abilities (e.g., Klingberg et al. 2005) seem particularly relevant for children with ADHD-only. Otherwise, the observation that children with ADHD+ODD profit more from reward and penalty than children with ADHD-only suggest that behavioral interventions that make use of rewards and penalties to shape behavior (mediation therapy) may be especially effective in the comorbid group. Rewards may have a distracting impact on performance of children with ADHD, especially when they try to work 'as quickly as possible' to obtain a reward.

Open Access This article is distributed under the terms of the Creative Commons Attribution Noncommercial License which permits any noncommercial use, distribution, and reproduction in any medium, provided the original author(s) and source are credited.

\section{References}

Achenbach, T. M., \& Edelbrock, C. S. (1981). Behavioral problems and competencies reported by parents of normal and disturbed children aged four through sixteen. Monographs of the Society for Research in Child Development, 46, 1-82.

Albrecht, B., Banaschewski, T., Brandeis, D., Heinrich, H., \& Rothenberger, A. (2005). Response inhibition deficits in externalizing child psychiatric disorders: an ERP-study with the Stoptask. Behavioral and Brain Functions, 1, 22.

Alderson, R. M., Rapport, M. D., \& Kofler, M. J. (2007). Attentiondeficit/hyperactivity disorder and behavioral inhibition: a metaanalytic review of the stop-signal paradigm. Journal of Abnormal Child Psychology, 35, 745-758.

American Psychiatric Association (2000). Diagnostic and statistical manual of mental disorders (TR) (4th ed.). Washington, DC: Author.

Angold, A., Costello, E., \& Erkanli, A. (1999). Comorbidity. Journal of Child Psychology and Psychiatry, 40, 55-87.

Banaschewski, T., Brandeis, D., Heinrich, H., Albrecht, B., Brunner, E., \& Rothenberger, A. (2003). Association of ADHD and conduct disorder-brain electrical evidence for the existence of a distinct subtype. Journal of Child Psychology and Psychiatry, 44, 356-376.

Barkley, R. A. (1997). Behavioral inhibition, sustained attention, and executive functions: constructing a unifying theory of ADHD. Psychological Bulletin, 121, 65-94.
Barratt, E. S., \& Patton, J. H. (1983). Impulsivity: Cognitive, behavioral and psychophysiological correlates. In M. Zuckerman (Ed.), Biological bases of sensation seeking, impulsivity and anxiety (pp. 77-122). Hillsdale, NJ: Erlbaum.

Biederman, J., Faraone, S. V., Milberger, S., Jetton, J. G., Chen, L., Mick, E., et al. (1996). Is childhood oppositional defiant disorder a precursor to adolescent conduct disorder? Findings from a fouryear follow-up study of children with ADHD. Journal of the American Academy of Child and Adolescent Psychiatry, 35, 1193-1204.

Bush, G., Valera, E. M., \& Seidman, L. J. (2005). Functional neuroimaging of attention-deficit/hyperactivity disorder: a review and suggested future directions. Biological Psychiatry, 57, 12731284.

Casey, B. J., Nigg, J. T., \& Durston, S. (2007). New potential leads in the biology and treatment of attention deficit-hyperactivity disorder. Current Opinion in Neurology, 20, 119-124.

Castellanos, F. X., \& Tannock, R. (2002). Neuroscience of attentiondeficit/hyperactivity disorder: the search for endophenotypes. Nature Reviews Neuroscience, 3, 617-628.

Clarke, A. R., Barry, R. J., McCarthy, R., \& Selikowitz, M. (2002). Children with attention-deficit/hyperactivity disorder and comorbid oppositional defiant disorder: an EEG analysis. Psychiatry Research, 111, 181-190.

Cohen, J. (1988). Statistical power analysis for the behavioral sciences (2nd ed.). New Jersey: Erlbaum.

Daugherty, T. K., \& Quay, H. C. (1991). Response perseveration and delayed responding in childhood behavior disorders. Journal of Child Psychology and Psychiatry, 32, 453-461.

Dougherty, D. M., Dew, R. E., Mathias, C. W., Marsh, D. M., Addicott, M. A., \& Barratt, E. S. (2007). Impulsive and premeditated subtypes of aggression in conduct disorder: differences in time estimation. Aggressive Behavior, 33, 574-582.

Douglas, V. I. (1989). Can Skinnerian theory explain attention deficit disorder. A reply to Barkley. In L. M. Bloomingdale \& J. A. Sergeant (Eds.), Attention deficit disorder: Current concepts and emerging trends in attentional and behavioral disorders of childhood (pp. 235-254). Elmsford, NY: Pergamon.

Doyle, A. E., Willcutt, E. G., Seidman, L. J., Biederman, J., Chouinard, V. A., Silva, J., et al. (2005). Attention-deficit/ hyperactivity disorder endophenotypes. Biological Psychiatry, 57, 1324-1335.

Eaves, L. J., Silberg, J. L., Meyer, J. M., Maes, H. H., Simonoff, E., Pickles, A., et al. (1997). Genetics and developmental psychopathology: 2. The main effects of genes and environment on behavioral problems in the Virginia Twin Study of Adolescent Behavioral Development. Journal of Child Psychology and Psychiatry, 38, 965-980.

Fonseca, A. C., \& Yule, W. (1995). Personality and antisocialbehavior in children and adolescents - an inquiry into Eysenck's and Gray's theories. Journal of Abnormal Child Psychology, 23, $767-781$.

Geary, D. C. (1993). Mathematical disabilities: cognitive, neuropsychological, and genetic components. Psychological Bulletin, 114, 345-362.

Groth-Marnat, G. (1997). Handbook of psychological assessment (3rd ed.). New York: Wiley.

Herpertz, S. C., Wenning, B., Mueller, B., Qunaibi, M., Sass, H., \& Herpertz-Dahlmann, B. (2001). Psychophysiological responses in ADHD boys with and without conduct disorder: Implications for adult antisocial behavior. Journal of the American Academy of Child and Adolescent Psychiatry, 40, 1222-1230.

Hogan, A. E. (1999). Cognitive functioning in children with oppositional defiant disorder and conduct disorder. In H. Quay \& A. E. Hogan (Eds.), Handbook of disruptive behavior disorders (pp. 317-335). New York: Plenum. 
Ivry, R. B. (1996). The representation of temporal information in perception and motor control. Current Opinion in Neurobiology, 6, 851-857.

Karatekin, C., Markiewicz, S. W., \& Siegel, M. A. (2003). A preliminary study of motor problems in children with attentiondeficit/hyperactivity disorder. Perceptual and Motor Skills, 97, $1267-1280$.

Kirk, R. E. (1968). Experimental design: Procedures for the behavioral sciences. Monterey, CA: Brooks/Cole.

Klingberg, T., Fernell, E., Olesen, P. J., Johnson, M., Gustafsson, P., Dahlström, K., et al. (2005). Computerized training of working memory in children with ADHD - a randomized, controlled trial. Journal of the American Academy of Child and Adolescent Psychiatry, 44, 177-186.

Leth-Steensen, C., Elbaz, Z. K., \& Douglas, V. I. (2000). Mean response times, variability, and skew in the responding of ADHD children: a response time distributional approach. Acta Psychologica, 104, 167-190.

Lezak, M. D. (2004). Neuropsychological assessment (4th ed.). New York: Oxford University Press.

Loeber, R., Burke, J. D., Lahey, B. B., Winters, A., \& Zera, M. (2000). Oppositional defiant and conduct disorder: a review of the past 10 years, part I. Journal of the American Academy of Child and Adolescent Psychiatry, 39, 1468-1484.

Logan, G. D., Cowan, W. B., \& Davis, K. A. (1984). On the ability to inhibit simple and choice reaction time responses: a model and a method. Journal of Experimantal Psychology: Human Perception and Performance, 10, 276-291.

Logan, G. D., Schachar, R. J., \& Tannock, R. (1997). Impulsivity and inhibitory control. Psychological Science, 8, 60-64.

Luman, M., Oosterlaan, J., \& Sergeant, J. A. (2005). The impact of reinforcement contingencies on $\mathrm{AD} / \mathrm{HD}$ : a review and theoretical appraisal. Clinical Psychology Review, 25, 183-213.

Luman, M., Oosterlaan, J., \& Sergeant, J. A. (2008). Affective modulation of response timing in ADHD: the impact of reinforcement valence and magnitude. Journal of Abnormal Child psychology, 36, 445-456.

Matthys, W., Van Goozen, S. H. M., De Vries, H., Cohen-Kettenis, P. T., \& Van Engeland, H. (1998). The dominance of behavioural activation over behavioural inhibition in conduct disordered boys with or without attention deficit hyperactivity disorder. Journal of Child Psychology and Psychiatry, 39, 643-651.

Miltner, W. H. R., Braun, C. H., \& Coles, M. G. H. (1997). Eventrelated brain potentials following incorrect feedback in a timeestimation task: evidence for a generic neural system for error detection. Journal of Cognitive Neuroscience, 9, 788-798.

Morgan, A. B., \& Lilienfeld, S. O. (2000). A meta-analytic review of the relation between antisocial behavior and neuropsychological measures of executive function. Clinical Psychology Review, 20, 113-136.

Newman, J. P., \& Wallace, J. F. (1993). Diverse pathways to deficient self-regulation-implications for disinhibitory psychopathology in children. Clinical Psychology Review, 13, 699-720.

O’brien, B. S., \& Frick, P. J. (1996). Reward dominance: associations with anxiety, conduct problems, and psychopathy in children. Journal of Abnormal Child Psychology, 24, 223-240.

Oosterlaan, J., Logan, G. D., \& Sergeant, J. A. (1998). Response inhibition in $\mathrm{AD} / \mathrm{HD}, \mathrm{CD}$, comorbid $\mathrm{AD} / \mathrm{HD}+\mathrm{CD}$, anxious, and control children: A meta-analysis of studies with the stop task. Journal of Child Psychology and Psychiatry, 39, 411-425.

Oosterlaan, J., Scheres, A., \& Sergeant, J. A. (2005). Which executive functioning deficits are associated with $\mathrm{AD} / \mathrm{HD}, \mathrm{ODD} / \mathrm{CD}$ and comorbid AD/HD+ODD/CD? Journal of Abnormal Child Psychology, 33, 69-85.

Pelham, W. E., Evans, S. W., Gnagy, E. M., \& Greenslade, K. E. (1992). Teacher ratings of DSM-III-R symptoms for the disruptive behavior disorders - prevalence, factor-analyses, and conditional probabilities in a special-education sample. School Psychology Review, 21, 285-299.

Pelham, W. E., Aronoff, H. R., Midlam, J. K., Shapiro, C. J., Gnagy, E. M., Chronis, A. M., et al. (1999). A comparison of Ritalin and Adderall: Efficacy and time-course in children with attentiondeficit/ hyperactivity disorder. Pediatrics, 103, e43.

Pennington, B. F., \& Ozonoff, S. (1996). Executive functions and developmental psychopathology. Journal of Child Psychology and Psychiatry, 37, 51-87.

Pliszka, S. R. (2000). Patterns of psychiatric comorbidity with attention-deficit/hyperactivity disorder. Child and Adolescent Psychiatric Clinics of North America, 9, 525-540.

Quay, H. C. (1997). Inhibition and attention deficit hyperactivity disorder. Journal of Abnormal Child Psychology, 25, 7-13.

Raine, A. (1993). The psychopathology of crime: Criminal behavior as a clinical disorder. San Diego: Academic.

Rubia, K., Halari, R., Smith, A. B., Mohammad, M., Scott, S., Giampietro, V., et al. (2008). Dissociated functional brain abnormalities of inhibition in boys with pure Conduct disorder and in boys with pure attention-deficit/hyperactivity disorder. American Journal of Psychiatry, 165, 889-897.

Russell, V. A., Oades, R. D., Tannock, R., Killeen, P. R., Auerbach, J. G., Johansen, E. B., et al. (2006). Response variability in attention-deficit/ hyperactivity disorder: a neuronal and glial energetics hypothesis. Behavioral and Brain Functions, 23, 2-30.

Rutter, M. (1997). Comorbidity: concepts, claims and choices. Criminal Behaviour and Mental Health, 7, 265-285.

Sagvolden, T., Johansen, E. B., Aase, H., \& Russell, V. A. (2005). A dynamic developmental theory of attention-deficit/hyperactivity disorder (ADHD) predominantly hyperactive/impulsive and combined subtypes. Behavioral and Brain Sciences, 28, 397-419.

Scheres, A., Oosterlaan, J., \& Sergeant, J. A. (2001). Response inhibition in children with DSM-IV subtypes of $\mathrm{AD} / \mathrm{HD}$ and related disruptive disorders: the role of reward. Child Neuropsychology, 7, 172-189.

Scheres, A., Milham, M. P., Knutson, B., \& Castellanos, F. X. (2007). Ventral striatal hyporesponsiveness during reward anticipation in attention-deficit/hyperactivity disorder. Biologial Psychiatry, 61, $720-724$.

Séguin, J. R., Nagin, D., Assaad, J. M., \& Tremblay, R. E. (2004). Cognitive-neuropsychological function in chronic physical aggression and hyperactivity. Journal of Abnormal Psychology, $113,603-613$.

Seidman, L. J., Valera, E. M., \& Makris, N. (2005). Structural brain imaging of attention-deficit/hyperactivity disorder. Biological Psychiatry, 57, 1263-1272.

Semrud-Clikeman, M., Steingard, R. J., Filipek, P., Biederman, J., Bekken, K., \& Renshaw, P. F. (2000). Using MRI to examine brain-behavior relationships in males with attention deficit disorder with hyperactivity. Journal of the American Academy of Child and Adolescent Psychiatry, 39, 477-484.

Sergeant, J. A., Oosterlaan, J., \& Van der Meere, J. J. (1999). Information processing in attention-deficit/ hyperactivity disorder. In H. C. Quay \& A. E. Hogan (Eds.), Handbook of disruptive behavior disorders (pp. 75-104). New York: Plenum.

Sergeant, J. A., Geurts, H., \& Oosterlaan, J. (2002). How specific is a deficit of executive functioning for attention-deficit/hyperactivity disorder? Behavioural Brain Research, 130, 3-28.

Shaffer, D., Fisher, P., Lucas, C. P., Dulcan, M. K., \& Schwab-Stone, M. E. (2000). NIMH diagnostic interview schedule for children version IV (NIMH DISC-IV): description, differences from previous versions, and reliability of some common diagnoses. Journal of the American Academy of Child and Adolescent Psychiatry, 39, 28-38.

Sonuga-Barke, E. J. (2002). Psychological heterogeneity in AD/HD-a dual pathway model of behaviour and cognition. Behavioural Brain Research, 10, 29-36. 
Stuss, D. T., Murphy, K. J., Binns, M. A., \& Alexander, M. P. (2003). Staying on the job: the frontal lobes control individual performance variability. Brain, 126, 2363-2380.

Thapar, A., Holmes, J., Poulton, K., \& Harrington, R. (1999). Genetic basis of attention deficit hyperactivity. British Journal of Psychiatry, 174, 105-111.

Toplak, M. E., Dockstader, C., \& Tannock, R. (2006). Temporal information processing in ADHD: findings to date and new methods. Journal of Neuroscience Methods, 151, 15-29.

Tripp, G., \& Wickens, J. (2008). From neurobiology to behavior: reinforcement mechanisms in ADHD. Journal of Child Psychology and Psychiatry, 49, 691-704.
Van Goozen, S. H., Cohen-Kettenis, P. T., Snoek, H., Matthys, W., Swaab-Barneveld, H., \& van Engeland, H. (2004). Executive functioning in children: a comparison of hospitalised ODD and ODD/ADHD children and normal controls. Journal of Child Psychology and Psychiatry, 45, 284-292.

Willcutt, E. G., Sonuga-Barke, E. J. S., Nigg, J. T., \& Sergeant, J. A. (2008). Recent developments in neuropsychological models of childhood psychiatric disorders. Advances in Biological Psychiatry, 24, 195-226.

Wing, A. M., \& Kristofferson, A. B. (1973). Response delays and the timing of discrete motor responses. Perception and Psychophysics, $14,5-12$. 